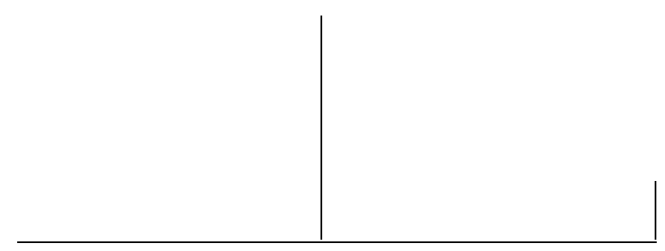

Rev. Latinoam. Psicopat. Fund., VI, 1, 109-129

\title{
Semiologia e características clínicas das crises pseudo-epilépticas
}

Florindo Stella

Mário Eduardo Costa Pereira

Os autores discutem as características semiológicas e clínicas de crises não-epilépticas psicogênicas e o papel de elementos de natureza inconsciente na gênese desses fenômenos. Essas crises constituem condição psicopatológica relativamente freqüente em centros de atendimento de pacientes portadores de epilepsia e em serviços de emergência psiquiátrica. O diagnóstico diferencial entre ambos os quadros nem sempre representa tarefa fácil e exige do clínico conhecimento das manifestações semiológicas tanto de crises genuinamente epilépticas, como de crises conversivas, de natureza essencialmente psicogênica.

Palavras-chave: Transtorno conversivo, crises pseudoepilépticas, crises psicogênicas, semiologia 


\section{Introdução}

É comum escutar-se entre os profissionais da área de saúde mental que a histeria dos tempos de Charcot não existe mais, e que o Grande Ataque Histérico é uma forma psicopatológica que talvez só tenha existido de fato na Salpêtrière do século XIX. Contudo, a verdade é que as manifestações mais exuberantes do espectro histérico continuam amplamente presentes nas sociedades ocidentais. Evidentemente esses estados têm novas inscrições na cultura e são menos comuns no contexto do consultório dos clínicos, mas nem por isso deixam de ter enorme relevância prática e científica, incluindo-se aqui sua frequiência como causa de procura de cuidados técnicos especializados.

O presente artigo visa tratar especificamente de uma forma de manifestação psicopatológica - em geral de natureza histérica - muito comum, muito florida em sua expressão clínica e que coloca-se como desafio para os campos da psiquiatria, da neurologia e da psicanálise. Aborda-se aqui a natureza dos quadros em que o indivíduo inconscientemente mimetiza com seu comportamento um ataque epiléptico, sem apresentar o substrato neuro-elétrico correspondente à epilepsia.

As chamadas pseudocrises têm sido motivo de inúmeras controvérsias entre os profissionais que cuidam de pacientes com epilepsia. Uma longa história de encontros e desencontros, sobreposições e diferenciações clínicas precedem os debates atuais que visam separar as manifestações especificamente epilépticas de outras formas de quadros convulsivos de origem psíquica, sobretudo daqueles de natureza histérica. Já em seus trabalhos pioneiros sobre a his- 


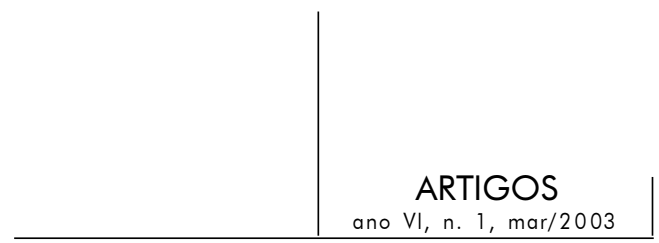

teria, no final do século XIX, Jean-Martin Charcot descrevera a "fase epileptóide" como sendo uma das etapas do "Grande Ataque Histérico". Esta era caracterizada justamente pelo rebaixamento do nível de consciência e aumento do tônus muscular, intercalado por agitação clônica dos membros e tronco (Charcot, 1999; Pereira, 1999). Quando o quadro histérico apresentava-se sob sua forma completa, incluindo tanto os estigmas crônicos, quanto o Grande Ataque, com sua fase epileptóide, Charcot denominava-o de "hístero-epilepsia". Apesar do grande esforço do mestre francês por inscrever esses estados no campo da patologia neurológica, a história e os avanços dos conhecimentos anátomo-clínicos e psicopatológicos acabaram por fazer da histeria, antes, uma entidade psiquiátrica; embora suas manifestações, como veremos, impliquem todo o domínio da clínica médica, sobretudo da neurologia.

O termo pseudocrise é permeado por conotação no mínimo errônea, quando não abertamente pejorativa. Pacientes, ao ouvirem do médico que são portadores de tal transtorno, com freqüência discordam deste diagnóstico, uma vez que para eles suas crises se apresentam como bastante reais. Podem não identificar os fatores desencadeantes e, menos ainda, a dinâmica psíquica que propicia a deflagração do evento aparentemente epiléptico. Porém, eles sabem que têm crises. Nos últimos anos, tem havido uma preocupação, por parte dos especialistas, em substituir a denominação pseudocrise pela de crise pseudoepiléptica ou crise não-epiléptica psicogênica, entre outras. Esta mudança baseiase na constatação de que o paciente, ao apresentar convulsão psicogênica, de fato apresenta uma crise real do ponto de vista daquele que a experimenta, embora não originada em alterações bioelétricas cerebrais próprias de uma crise epiléptica. Sua origem está associada a processos psíquicos geralmente inconscientes, conduzindo a manifestações sintomáticas de natureza dissociativa e conversiva muito semelhantes aos ataques epilépticos do tipo "Grande Mal". Portanto, afirmar-se que o evento é uma pseudocrise parece negar preconceituosamente o sofrimento do paciente, e não contribui para a compreensão do fenômeno.

Além disso, a existência e a grande frequiência desses eventos psicopatológicos contradizem a idéia amplamente difundida de que os fenômenos maiores da histeria e o chamado ataque histérico praticamente estariam desaparecidos de nossas sociedades urbanas ocidentais. Pelo contrário, as crises pseudo-epilépticas constituem apenas uma das inúmeras formas sob as quais o ataque histérico subsiste na cultura contemporânea.

O propósito deste artigo é, pois, o de discutir a natureza e as características semiológicas das crises pseudo-epilépticas, designação adotada neste trabalho, salientando-se a atualidade dessa manifestação psicopatológica, bem como suas relações com a histeria. 
Aspectos históricos da compreensão médica dos quadros convulsivos

O termo "convulsão", segundo o Novo Dicionário Aurélio (Ferreira, 1999, p. 549), tem uma acepção leiga que indica "grande agitação ou transformação" e "ato ou efeito de convulsionar", ou seja, ele remete ao campo daquilo que promove agitação, que conturba e excita. Seu espectro semântico não deixa de evocar a idéia de "revolução" e de "agitação das massas". A própria noção de "crise" não lhe é estranha. Dito de outra forma, "convulsão" evoca algo que agita, excita e interpela: o Sujeito e o Outro.

No contexto médico, esse termo traduz um estado clínico em que o indivíduo apresenta contrações musculares súbitas, involuntárias e violentas. Essas contrações podem ser constantes, mantendo os músculos em contração contínua (tônicas) ou rítmicas e espasmódicas (clônicas), ou ainda uma combinação das duas formas anteriores (tônico-clônicas). Sob qualquer dessas apresentações clínicas, são quadros muito expressivos, intensos e que normalmente interpelam aqueles que os assistem, provocando perturbação e ímpetos de "se fazer alguma coisa". Essa dimensão de agitação subjetiva e de interpelação do outro é fundamental para se situar histórica e antropologicamente a evolução das concepções médicas sobre os quadros convulsivos.

Podendo estar presentes em diversas espécies de condições psicológicas, as convulsões sempre colocaram o problema da delimitação de sua origem, sobretudo quanto à sua relação com processos corporais ou com "crises" de natureza psíquica.

A medicina romana clássica já distinguia, a partir de critérios clínicos objetivos, histeria de epilepsia. Assim, Celso, em seu Tratado de medicina, sustentava que a histeria "tira por vezes a consciência e provoca a queda, como a epilepsia. [...] difere desta por não haver reviravolta dos olhos, nem espuma na boca, nem convulsões, mas somente adormecimento profundo" (Cf. Trillat, 1991, p. 25). Também Areteu da Capadócia destaca a semelhança entre essas duas entidades patológicas, sobretudo pelo fato de que em ambas ocorrem a sensação de sufocação e o prejuízo da consciência. Por outro lado, Areteu, tal como Celso, considerava que a presença de convulsões seria específica da epilepsia.

A tradição médica que se estabeleceu na descrição do quadro histérico e que permaneceu ao longo dos séculos delimitava a crise histérica como iniciando por uma "aura", seguida de uma fase convulsiva, "expressões emocionais ou afetivas, perturbações do entendimento com delírio mais ou menos onírico, a possível aparição de uma 'apoplexia histérica' que não é outra senão a catalepsia com seu estado de morte aparente; o fim do acesso por diminuição progressiva 


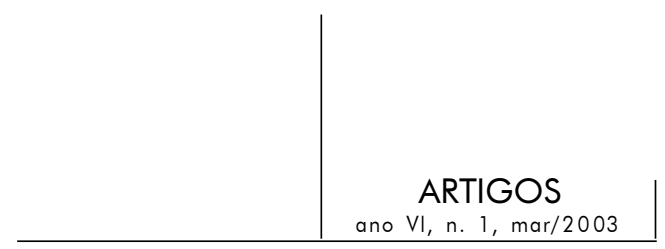

dos acidentes é marcado pela emissão de urinas claras abundantes e pela expulsão de excreções útero-vaginais acompanhadas, por vezes, de sensações voluptuosas" (Trillat, 1991, p. 114).

No século XIX, a distinção clínica entre os dois quadros revestia-se de nova importância pois considerava-se que a histeria, diferentemente da epilepsia, seria curável pelo tratamento moral.

Retomando a teoria clássica, sobretudo a visão de Areteu da Capadócia, Pinel considerava que o útero seria a sede da histeria e que seu desencadeamento decorria de uma continência sexual austera. Será apenas Georget (1795-1828), um aluno de Esquirol, que tomará maior consistência à noção segundo a qual a histeria constitui um fenômeno cerebral, tal como a hipocondria e a própria epilepsia. As três entidades - localizadas no aparelho ao qual se atribuem as funções psíquicas superiores, as emoções e os afetos - passam a colocar, da forma mais urgente, o problema da discriminação psicopatológica e nosográfica entre elas (Cf. Trillat, 1991, p. 117).

Observa-se ao longo do século XIX uma progressiva tensão quanto à localização da histeria: uterina ou cerebral? A hipótese cerebral vai ganhando importância, o que coloca o problema de se estabelecer a suposta fisiopatologia para aqueles que, rejeitando a hipótese da simulação, atribuíam um estatuto nosológico à histeria.

O próprio Georget já havia chamado a atenção para o fato de que os sintomas histéricos e epilépticos freqüentemente coexistem em um mesmo paciente, mesclando-se de forma muito estreita.

Cerise, por sua vez, aponta a presença de acessos espasmódicos e convulsivos como específicos da histeria, permitindo diferenciá-la da hipocondria.

Para elucidar o problema da "natureza" da histeria era necessário previamente o estabelecimento de sua forma natural. Nesse sentido, o trabalho de Charles Lasègue desempenhou um papel decisivo. Esse grande clínico francês deu-se a tarefa de descrever minuciosamente as diferentes formas sintomáticas do transtorno histérico. Sua abordagem é claramente analítica, no sentido de que busca dissecar as formas sempre mutantes da histeria, na esperança de encontrar suas estruturas fixas e constantes. Por fim, Lasègue chega à sua famosa conclusão: "A definição de histeria jamais foi dada e jamais o será", fundando sua posição no fato de que os sintomas dela são excessivamente variáveis, impedindo assim que se estabeleça a regularidade indispensável para a construção de uma entidade nosológica específica (Cf. Pereira, 1998).

É nesse contexto de investigação psicopatológica que viria a se inscrever o trabalho crucial de Jean-Martin Charcot, clínico e cientista, cuja obra seria um marco na consolidação da histeria como entidade psicopatológica autônoma e na separação de águas entre epilepsia e histeria. 


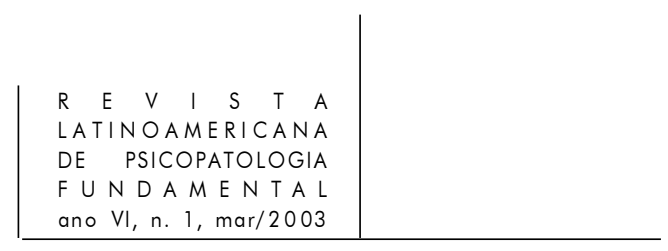

O essencial de sua contribuição derivou do método por ele introduzido no estudo dos fenômenos convulsivos, o qual já havia mostrado sua pertinência na construção da neurologia nascente: o método anátomo-clínico. Essa abordagem consistia em delimitar da maneira mais clara possível as formas clínicas típicas de cada patologia neurológica, diferenciando-as de manifestações "frustras" ou mistas. Em seguida, o exame anátomo-patológico demonstraria a existência de lesões específicas do sistema nervoso, às quais seriam imputadas as manifestações sintomáticas.

Tal método mostrou-se extremamente eficaz na delimitação de patologias como a esclerose em placas, as artropatias tabéticas e o mal de Parkinson. Por sua vez, sua aplicação aos fenômenos convulsivos impõe-se a Charcot de forma relativamente acidental, em um momento em que o essencial de sua obra neurológica já havia sido produzido.

Trillat (1991) lembra que em 1870 o serviço de Delasiauve no hospital da Salpêtrière, encontrando-se em um estado de péssimas condições de conservação, precisou ser submetido a extensos trabalhos de reforma. Os pacientes daquele pavilhão - que reunia alienados, epilépticos e histéricos, sem qualquer critério nítido de separação entre eles - seriam transferidos para outras unidades. Essa mistura de formas clínicas ocorria sobretudo por não existirem ainda critérios claros para separá-los sob uma perspectiva nosológica. Além disso, o agrupamento segundo as formas clínicas específicas constituía uma necessidade para a pesquisa. Assim, os pacientes foram separados segundo um critério clínico maior: a existência ou não de "crises" e o novo serviço - o Quartier des épileptiques simples - foi confiado a Charcot.

Até aquele momento, epilepsia simples e histeria eram concebidas como formas de "neurose", ou seja, alterações decorrentes de um funcionamento inadequado do sistema nervoso. Etienne Trillat, em sua apresentação a uma coletânea de artigos de Charcot sobre a histeria, lembra que "a histeria e a epilepsia [eram consideradas] as "duas grandes neuroses' e se opõem à simulação" (Trillat, 1971, p. 13). Ambas apresentavam "ataques" e "quadros convulsivos" em suas manifestações clínicas, e em nenhuma delas era possível demonstrar a presença de lesões específicas no exame anátomo-patológico do sistema nervoso dos indivíduos acometidos.

Delasiauve, acima mencionado, já havia ele próprio desempenhado um papel importante na discriminação dessas duas entidades com a publicação, em 1854, de seu Traité de l'épilepsie. Segundo sua visão, a epilepsia apresentaria sintomas mais "cerebrais", enquanto os da histeria seriam mais "torácicos", enfatizando assim seus aspectos ligados à angústia. Ele estabelece uma série de critérios clínicos distinguindo as duas entidades, em particular o caráter vago, irregular e preponderantemente clônico das convulsões histéricas, além do prognóstico mais 


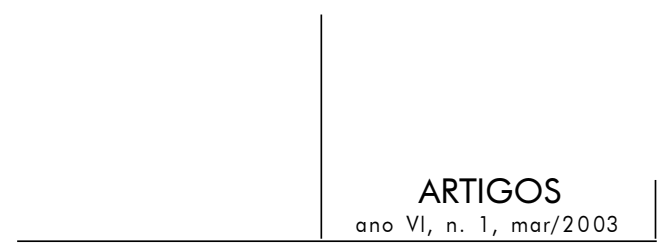

favorável a longo prazo dessas últimas. Havia, assim, no contexto da Salpêtrière, a estranha situação em que alguns dos mais importantes estudiosos dos fenômenos convulsivos trabalhavam em um serviço que de forma alguma, até então, procedera uma separação clínica concreta daqueles dois grupos de pacientes.

Dessa forma, àquela massa indistinta de pacientes convulsivos, Charcot aplica seu método anátomo-clínico. Todo o esforço do mestre francês voltavase a conferir à histeria um estatuto de doença neurológica como as outras. Para isso, era necessário, em primeiro lugar, demonstrar a tipicidade de suas manifestações clínicas. Charcot propõe, então, a descrição da "grande histeria" repousando sobre duas dimensões fundamentais: os sintomas histéricos permanentes (os chamados "estigmas" histéricos) e a hístero-epilepsia (o "Grande Ataque Histérico"). Esta, em sua forma completa, era descrita a partir do paradigma de estabilidade das fases dos sintomas ao longo das crises da epilepsia.

O Grande Ataque Histérico - na visão de Charcot - era composto por quatro fases, que se encadeariam segundo uma seqüência típica. Em outro artigo, descrevemos assim a evolução do ataque:

Após um certo período prodrômico de "aura histérica", com "distanciamento" do contato com o mundo imediato, agitação, confusão e mesmo de dores (sobretudo ovarianas) iniciaria a primeira fase do ataque: a fase epileptóide, a qual manifesta-se por aumento do tônus muscular (contração localizada ou generalizada da musculatura) intercalado por agitação clônica dos membros e do tronco. É o período que mais se assemelha a uma crise epiléptica. Nessa fase ocorreria, por vezes, o chamado "arco histérico": a paciente colocase num estado de tal contratura muscular que seu corpo curva-se, apoiado na cabeça e nos calcanhares. Em seguida, instala-se o período de clownismo, manifestado por posturas e atitudes bizarras. A conduta da paciente é francamente infantil e inconseqüente. O corpo assume posturas estranhas e de caráter por vezes grotesco. A terceira etapa é a das atitudes passionais, durante a qual a paciente mostraria expressões de beatitude, de enamoramento, de terror ou de outras formas de experiência afetiva intensa. A teatralidade do ataque encontra aqui seu ponto culminante. Finalmente, a resolução ocorreria em um período de delírio, durante o qual a paciente parece confusa ou em estado de fuga e passa a falar de forma incompreensível, irracional, dizer obscenidades ou, ainda, a revelar segredos e pensamentos íntimos. Quando todas essas etapas manifestam-se integralmente e nessa seqüência "canônica" teríamos o grande ataque histérico. As formes frustes ou petite hystérie seriam aquelas onde uma ou mais fases são omitidas, aparecem fora de ordem ou são muito brandas. (Pereira, 1999, p. 163)

Dessa maneira, Charcot consegue delimitar um quadro típico da histeria, buscando na estabilidade dessa apresentação a justificativa para fazê-la entrar como 


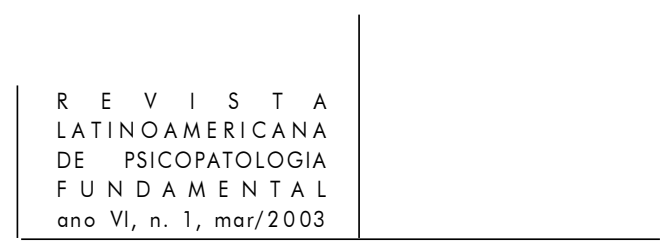

entidade nosológica de direito no campo do conhecimento médico. Por outro lado, o recurso à hipnose permitia desenvolver artificialmente os sintomas da histeria "natural" em mulheres histéricas. Assim, Charcot viria a sustentar que se tratava de uma neurose funcional do sistema nervoso central, explicação esta compatível com o fato de serem identificáveis lesões neurológicas típicas ao exame anátomopatológico.

A história e o avanço dos conhecimentos acabariam por demonstrar o equívoco da posição charcotiana. Contudo, os sujeitos histéricos continuaram a apresentar crises mimetizando a epilepsia mesmo fora dos muros da Salpêtrière.

No contexto atual, um grande número de trabalhos, sobretudo de perspectiva antropológica e de psiquiatria cultural têm sido realizados no sentido de descrever e especificar as formas atuais pelas quais se manifestam as formas maiores da antiga histeria, principalmente as que comportam sintomatologia dissociativa e/ou pseudoepiléptica. Kirmayer \& Santhanam (2000), da Division of Social and Transcultural Psychiatry da McGill University estudaram a histeria como manifestação antropológica contemporânea. Os autores mostram que os grandes acessos conversivos, tais como paralisias e mesmo as crises pseudoepilépticas têm diminuído de freqüência nos contextos urbanos ocidentalizados atuais. Contudo, elas permanecem como manifestações comumente observadas nos serviços de cuidados primários e especializados sob formas que justamente mimetizam transtornos neurológicos.

Além disso, processos sociais e culturais podem influenciar a expressão clínica dos transtornos conversivos de muitas formas. Entre eles, o artigo mencionado aponta: 1) a natureza das crenças e práticas relacionadas às doenças e à expressão do mal-estar que estas provocam; 2) a proeminência e disponibilidade social de mecanismos dissociativos; 3) a resposta da família, sistema de cuidados de saúde e dos sistemas sociais mais amplos aos tipos específicos de sintomas, incluindo o próprio conceito nosológico de histeria.

Assim, as condições locais de uma cultura podem propiciar formas clínicas e inscrições sociais específicas das manifestações conversivas.

Nesse contexto, cabe ressaltar o fenômeno brasileiro atual do grande aumento das religiões ditas evangélicas, freqüentemente marcadas por grande ascetismo e controle social da sexualidade, sobretudo de jovens e adolescentes. Tal fato reproduz, de certa forma, o ambiente de rigor e vigilância sobre a vida sexual dos indivíduos, tal como reinava na Europa do século XIX, palco dos grandes ataques histéricos, não infreqüentes atualmente em nossos serviços de urgência.

A seguir, descreveremos mais detalhadamente uma das formas contemporâneas mais freqüentemente observadas desses grandes acessos conversivos: as crises pseudoepilépticas. 


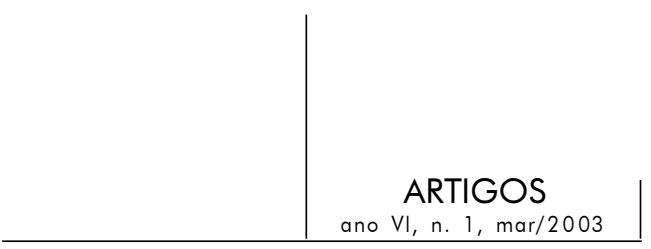

Dados socioculturais e epidemiológicos

Os transtornos conversivos do tipo crises convulsivas são mais freqüentes em pacientes epilépticos e em pessoas que tenham tido algum tipo de convivência com esses sujeitos, sendo que um terço deles têm crises epilépticas e crises pseudo-epilépticas como uma condição clínica coexistente (Kaplan et al., 1997). Porém, em serviços de atendimento psiquiátrico em hospitais gerais, estima-se que entre 5 e $15 \%$ dos atendimentos referem-se a pacientes com transtornos conversivos com características clínicas de convulsão não epiléptica, principalmente em mulheres jovens (Ibid.).

Estudo desenvolvido por Schenk \& Bear (1981), em quarenta pacientes com epilepsia de lobo temporal, evidenciou que 33\% deles apresentavam sintomas dissociativos e conversivos. Lelliot \& Fenwick (1991) relataram taxa de comorbidade entre epilepsia e crises pseudo-epilépticas em torno de $42 \%$. Outros estudos (Alper, 1994) relataram taxas entre 12 e 24\%. Estes autores afirmam que, nos pacientes com epilepsia e crises pseudo-epilépticas, com freqüência há comorbidade entre um transtorno dissociativo e outros quadros psicopatológicos, como transtornos depressivos, ansiedade e mesmo esquizofrenia. Kristensen \& Alving (1992) admitem que as taxas de crises pseudo-epilépticas são mais frequientes entre as mulheres com epilepsia, e que história de abuso sexual na infância e adolescência representam fator de risco para distúrbios conversivos.

Em trabalho de revisão, Marchetti (1998) constatou que, na população geral, a estimativa de prevalência desse fenômeno é de 5\%. Entretanto, em serviços que cuidam de pacientes com crises epilépticas de difícil controle, mesmo com tratamento medicamentoso apropriado, esta prevalência varia entre 20 e $33 \%$. Não estão claros os motivos pelos quais a prevalência de crises pseudo-epilépticas em pacientes epilépticos atinge percentuais significativamente mais elevados em comparação com a população geral. Porém, alguns autores admitem que o paciente, de forma inconsciente, "absorveria" a apresentação fenomenológica das crises epilépticas que ciclicamente já apresenta, provavelmente influenciado pelas descrições feitas por seus familiares e próximos, conferindo às crises não epilépticas, um quadro sintomatológico semelhante às crises epilépticas. Alguns estudos (Fiszman et al., 1997; Marchetti, 1998) apontam indicadores de risco para crises pseudo-epilépticas, como se segue. As mulheres são mais propensas a desenvolverem este transtorno, sobretudo aquelas que trabalham com pacientes epilépticos ou que mantêm contatos pessoais com eles. História psiquiátrica anterior, sobretudo relacionada com abuso físico, emocional e sexual na infância ou na adolescência e distúrbios mentais na família também representam fatores de risco para o desenvolvimento de transtornos conversivos em pacientes epilépticos. Transtornos de personalidade, sobretudo quando acompanhados de 


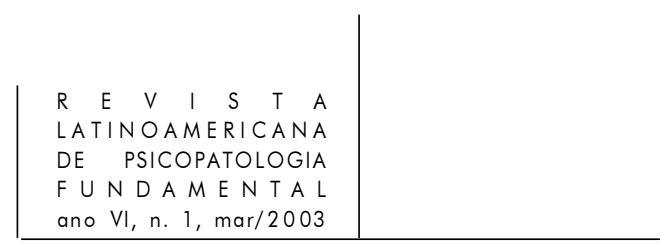

comportamento impulsivo e tentativas de suicídio, constituem fator de risco aumentado de crises pseudo-epilépticas.

\section{Características clínicas das crises pseudo-epilépticas}

As crises pseudo-epilépticas pertencem à categoria das convulsões dissociativas, segundo a classificação estabelecida pela CID-10 (OMS, 1993). Por sua vez, o DSM-IV (APA, 1995) classifica esses fenômenos dentro da categoria de transtornos conversivos.

De maneira geral, há consenso entre os critérios de diagnóstico estabelecidos pelo DSM-IV (APA, 1995) e pela CID-10 (OMS, 1993) no que tange às características clínicas dos fenômenos dissociativos e conversivos. O DSM-IV (1995) adota, para diagnóstico de transtorno conversivo, a presença de sintomas neurológicos do tipo motor ou sensorial, com a presença de componente psicológico, e inclui as pseudocrises entre as características clínicas do transtorno conversivo, denominando-as de pseudoconvulsões. Cabe lembrar que eventualmente não é fácil efetuar-se o diagnóstico diferencial entre uma crise epiléptica do tipo generalizado tônico-clônico e uma pseudoconvulsão de natureza conversiva, uma vez que as manifestações psicomotoras às vezes são parecidas. Além disso, em um terço dos pacientes que têm pseudocrises também coexistem crises epilépticas generalizadas tônico-clônicas, como mencionado anteriormente.

O termo "conversão" foi estabelecido por Freud, para quem o processo conversivo tem origem em conflitos de natureza inconsciente. Assim, neste processo, o sintoma somático (convulsão) representa uma resolução simbólica de um sofrimento psíquico de natureza inconsciente. A finalidade deste mecanismo consiste em reduzir a ansiedade, além de servir para manter este sofrimento fora do campo da consciência. Este processo pode ser designado de "ganho primário", uma vez que o paciente sente-se parcialmente aliviado da angústia derivada de seus conflitos inconscientes não solucionados. Além disso, por atender parcialmente a exigência pulsional intolerável ao eu, o sintoma constitui paradoxalmente uma forma de satisfação. Simultaneamente rejeitando e satisfazendo as diferentes tendências do conflito inconsciente, o sintoma histérico estrutura-se, no dizer de Freud, como uma "formação de compromisso". Portanto, ganho primário significa redução do sofrimento psíquico gerado pela angústia presente em situações conflitivas e que se manifestam mediante a ocorrência da crise conversiva. O próprio sintoma conversivo implica uma forma de gozo das tendências pulsionais impedidas pelo conflito de outra forma de satisfação. Assim, o desencadeamento das crises pseudo-epilépticas vem 


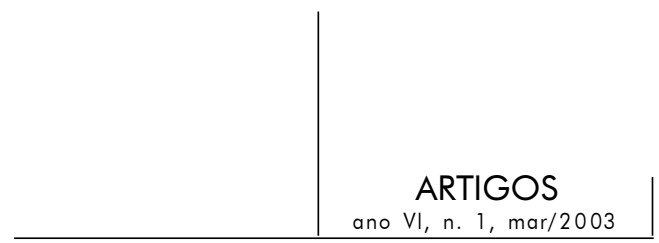

"resolver" a angústia primária, de origem inconsciente, além de permitir uma forma de satisfação, mesmo que a custo de grande sofrimento.

Segundo o DSM-IV (APA, 1995), o paciente com transtorno conversivo pode obter benefícios externos, em geral afetivos, esquiva de responsabilidades não desejadas, isenção de compromissos profissionais, além de atenção da equipe médica, ao manter-se doente: é o chamado "ganho secundário". Nesse contexto, ganho secundário refere-se às gratificações suplementares, geralmente de natureza regressiva, obtidas em conseqüência do surgimento dos sintomas, tais como os cuidados e atenção recebidos das pessoas que prestam assistência ao paciente na vigência da crise conversiva. Os cuidados destinados ao paciente, a proteção que lhe é conferida pela equipe médica e pelos familiares por ocasião de uma crise aparentemente epiléptica, mas cuja origem é de natureza psicogênica, representam esse ganho secundário, satisfação regressiva suplementar de tendências pulsionais represadas pelo conflito.

Para a CID-10 (OMS, 1993), transtorno "dissociativo" significa que o paciente está em estado vigil, mas sua consciência sofre comprometimento da integração normal entre a memória do passado, consciência de identidade, sensações imediatas e movimentos motores, ocorrendo, ainda, comprometimento do controle consciente seletivo sobre a atividade motora. Durante uma crise conversiva, o paciente permanece em estado vigil, apresentando, porém, comprometimento de determinadas funções, como identidade, memória, atividade sensorial e motora, que estão desagregadas.

Em resumo, tanto a CID-10 como o DSM-IV estabelecem que um transtorno conversivo constitui-se de uma constelação de sinais (o que se observa) e sintomas (o que o paciente relata) que refletem distúrbios das funções mentais, funções motoras voluntárias e sensoriais. Como conseqüência, há o comprometimento da coordenação psicomotora fina, do equilíbrio, além de convulsões epileptiformes de origem psíquica. Assim, o paciente pode apresentar movimentos tônico-clônicos não compatíveis com uma crise epiléptica, tanto em termos de duração como em termos semiológicos propriamente ditos. Ele pode, ainda, referir alterações das funções sensoriais, respondendo a estímulos dolorosos, o que não ocorre durante uma crise epiléptica verdadeira. Outra característica semiológica dos transtornos dissociativos/conversivos consiste na ausência de uma explicação objetiva que apóie a deflagração dos sinais e sintomas do quadro. Cabe lembrar que os movimentos "convulsivos" não respeitam as vias neuro-anatômicas responsáveis pela atividade motora e nem os mecanismos fisiopatológicos conhecidos. Eles se ajustam à maneira como o paciente vivencia e processa seu sofrimento psíquico originado no inconsciente.

Fatores psicológicos marcados por situações conflitivas de natureza inconsciente e a presença de estressores circunstanciais com freqüência são 


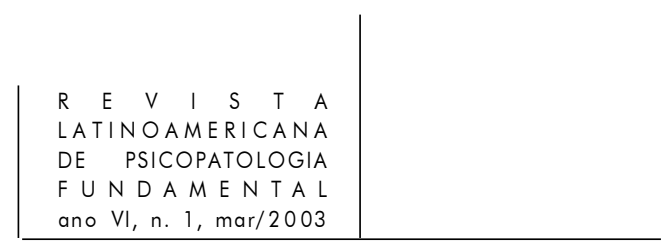

identificáveis na deflagração do episódio conversivo do tipo crise pseudoepiléptica. Esses elementos costumam preceder o evento. Freud (1908) mostrou que o processo conversivo (que se inseria no conjunto das manifestações da histeria) representava sofrimento psíquico intenso, com origem no inconsciente. Este sofrimento, vivenciado pelo paciente como angústia clinicamente importante, freqüentemente estava associado a conflitos não resolvidos na esfera sexual. As crises conversivas têm origem no inconsciente, não estando, pois, sob o controle volitivo do sujeito. Os sintomas não são intencionalmente produzidos, nem simulados pelo paciente. Portanto, elas não constituem um transtorno factício, que estaria baseado na simulação voluntária dos sintomas.

Como apontado anteriormente, as crises pseudo-epilépticas não são isentas de sofrimento psíquico. Para muitos pacientes, as crises trazem grande angústia, sentimento de impotência perante sua incapacidade de controlar o desencadeamento das mesmas e constrangimentos diante de outras pessoas. Além disso, com freqüência a recorrência desses episódios traz prejuízo para o funcionamento social e ocupacional, agravando o sofrimento psíquico existente.

Do ponto de vista semiológico, admite-se que, no caso das crises pseudoepilépticas, o transtorno conversivo expresse os conflitos intrapsíquicos inconscientes por meio de sintomas "neurológicos" caracterizados por alterações sensoriais (parestesias, distúrbios visuais) e motoras (movimentos convulsivos). A produção destes indicadores neurológicos obviamente não segue as vias neurais típicas. Este processo implica uma relação simbólica entre os elementos significantes do conflito, a angústia e os sintomas pseudoneurológicos, propiciando o alívio parcial e temporário do sofrimento. Há uma linguagem nãoverbal que expressa a tentativa de alívio do sofrimento psíquico (Gumnit, 1994). Neste sentido, o transtorno conversivo remete antes a um agrupamento de sintomas de origem psíquica do que a uma doença médica em sentido estrito. Como agrupamento de sintomas, ele pode representar uma resposta a um processo agudo ou a uma condição crônica que gera sofrimento psíquico. Como doença, o transtorno conversivo só poderia ser pensado na perspectiva de uma condição psíquica cujos mecanismos mentais são organizados e perpetuados no tempo (Betts, 1997).

Pessoas com níveis de escolaridade mais elevados tendem a apresentar sintomas mais sutis, mais refinados, enquanto que pessoas com escolaridade menor, culturalmente mais ingênuas ou desconhecedoras de assuntos médicos, tendem a demonstrar sintomas não plausíveis e, muitas vezes, bizarros. Obviamente, a capacidade de elaboração cognitiva está presente na constelação dos sintomas de uma crise pseudo-epiléptica.

Os critérios diagnósticos da CID-10 (OMS, 1993) e do DSM-IV (APA, 1995) de um processo dissociativo/conversivo envolvem a presença de sinais e sintomas aparentemente neurológicos, como parestesia em uma determinada área 


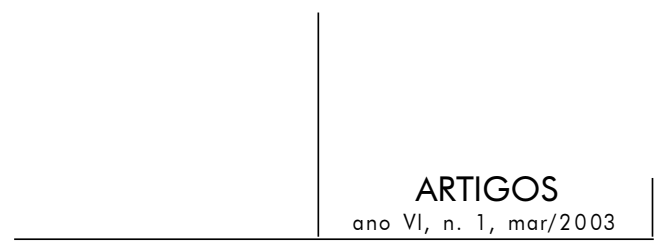

do corpo, movimentos convulsivos em algum membro ou quedas ao solo. $\mathrm{O}$ quadro costuma ser seguido de movimentos bizarros do tipo debater-se, sem que se respeite a inervação segmentar do organismo. $\mathrm{O}$ paciente pode apresentar paralisia de um membro, fraqueza muscular localizada, afonia e distúrbios visuais. O quadro sintomatológico pode variar de um episódio para outro, mas pode, também, manter uma certa estereotipia, sobretudo quando o paciente, anteriormente, já se sentiu aliviado do sofrimento psíquico ao vivenciar uma crise. Além disso, ele pode apresentar sintomas dissociativos, como desconexão das várias estruturas e funções que compõem o sistema psíquico: assim, há uma desconexão entre pensamento lógico, percepção, sensações, memória, capacidade de orientação no tempo e no espaço, auto-identidade, relacionamento interpessoal etc. O paciente não consegue processar seu funcionamento psíquico de forma sistêmica, integrada.

As crises pseudo-epilépticas podem ser consideradas como eventos histéricos em que as alterações presentes no fenômeno não obedecem à físiologia natural do órgão segundo suas disposições anátomo-funcionais (Ramandan, 1985). Os sintomas correspondem à representação imaginária e à utilização simbólica que o paciente imprime a um órgão ou à sua função. Dalgalarrondo (2000) sugere que, além dos sintomas e sinais psicomotores não compatíveis com a disposição do funcionamento biológico, o paciente apresenta alterações da consciência do tipo dissociativo caracterizadas por rebaixamento e afunilamento da consciência, denominados estado crepuscular histérico. No transtorno dissociativo podem ocorrer, ainda, amnésia dissociativa, despersonalização e desorientação autopsíquica e alopsíquica.

\section{Diagnóstico médico-psiquiátrico das crises pseudo-epilépticas}

O diagnóstico das crises pseudo-epilépticas supõe a realização de anamnese detalhada, exame psiquiátrico e exame neurológico minucioso, além da exclusão de crises epilépticas generalizadas tônico-clônicas.

Como já afirmado anteriormente, as crises pseudo-epilépticas são mais freqüentes em pacientes com epilepsia de origem em lobo temporal. Este tipo de epilepsia inicia-se em estruturas mesiais do sistema límbico, como o hipocampo (que processa a memória recente) e a amígdala (associada aos processos emocionais). Pacientes com alterações neurobiológicas nessas áreas teriam maior propensão tanto às crises epilépticas parciais complexas de difícil controle, como às crises não epilépticas psicogênicas (Lesser, 1985; Oana, 1998). Nas crises parciais complexas há comprometimento da consciência caracterizado por 


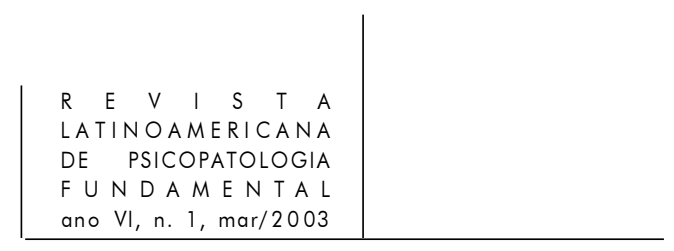

dificuldade ou impossibilidade de responsividade aos estímulos do meio, alterações da senso-percepção e confusão mental; e nas crises tônico-clônicas generalizadas há perda total da consciência. Por sua vez, nas crises pseudo-epilépticas há distúrbios da auto-identidade, memória e das funções senso-perceptivas e psicomotoras decorrentes da desintegração da consciência (Thomas and Trimble, 1997).

A condição epiléptica, por sua vez, pode desencadear dois tipos de distúrbios no estado mental do paciente epiléptico (Lesser, 1985): a) provocar alterações da consciência originadas da atividade bioelétrica cerebral anormal, particularmente durante as crises parciais complexas cujo início se dá no lobo temporal; b) provocar o surgimento de crises pseudo-epilépticas em pacientes epilépticos com características psicológicas propensas a esses fenômenos, isto é, naqueles com conflitos inconscientes, conforme já descrito.

\section{Semiologia das crises pseudo-epilépticas}

A descrição semiológica das crises pseudo-epilépticas passa por várias etapas (Fiszman et al., 1997; Marchetti, 1998; Oana, 1998; Stella, 2000; Dalgalarrondo, 2000):

Anamnese completa das crises pseudo-epilépticas:

- Início após a segunda década de vida.

- Alta freqüência das crises.

- Ausência de resposta às drogas anti-epilépticas.

- Remissões espontâneas.

- Ocorrência em locais fechados (em geral, na presença de outros).

- Ausência de incontinência ou mordedura de língua.

- Ausência de crises noturnas (durante o sono).

- Ausência de traumas durante as crises.

- Ausência de um padrão estereotipado das crises.

- Atendimentos de emergência freqüentes ou internações repetidas sem achados definidos.

- Sofrimento psíquico associado à história de abuso físico, emocional ou sexual na infância ou adolescência.

- Desencadeamento emocional claro ou específico.

- Ganho primário ou secundário.

- Aparente indiferença ou reação emocional excessiva durante a crise.

- Presença de transtornos psiquiátricos (depressão e ansiedade). 


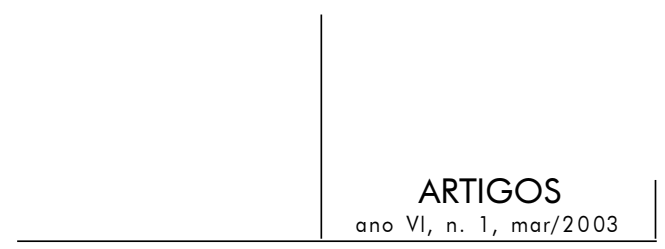

\section{Exame psiquiátrico:}

- Identificação de conflitos inconscientes, em geral de natureza histérica.

- Identificação de transtornos de personalidade.

- Caracterização de transtornos psiquiátricos associados, sobretudo, a depressão e risco de suicídio.

\section{Exame neurológico:}

- Em geral normal.

\section{Exames subsidiários:}

- Durante as crises pseudo-epilépticas os exames repetidos do tipo EEG (Eletrencefalograma), telemetria e vídeo-EEG são normais. Enquanto as crises epilépticas convulsivas apresentam padrão estereotipado dos movimentos motores, com perda da consciência, uma convulsão conversiva varia de uma crise para outra, sem perda da consciência, embora com alterações do estado mental. Além disso, durante uma crise epiléptica há um padrão eletrencefalográfico característico, com alterações bioelétricas cerebrais paroxísticas; na crise pseudo-epiléptica o EEG é normal, sem as alterações paroxísticas epilpetogênicas.

\section{Sinais e sintomas clínicos sugestivos de crise pseudo-epiléptica:}

- Início gradual, com pródromo variável e prolongado

(hiperventilação, cefaléia).

- Presença de evento emocional desencadeante.

- Duração prolongada.

- Movimentos de caráter intencional de extremidades caracterizados por atividade motora desordenada, abalos assincrônicos de braços e pernas, do tipo "debaterse", "agitar-se".

- Progressão não fisiológica e desordenada dos movimentos.

- Posturas distônicas, rigidez da musculatura do tronco e opistótono.

- Projeção pélvica, arqueamento do tronco.

- Balanço bilateral da cabeça.

- Não envolvimento da face durante a crise (como se o paciente estivesse distante).

- Ausência de cianose ou palidez.

- Ausência de sinais neurológicos anormais durante a crise ou no período pósictal imediato (o paciente mantém os reflexos).

- Preservação da resposta a estímulos ambientais durante a crise:

$>$ manutenção dos reflexos corneanos; 


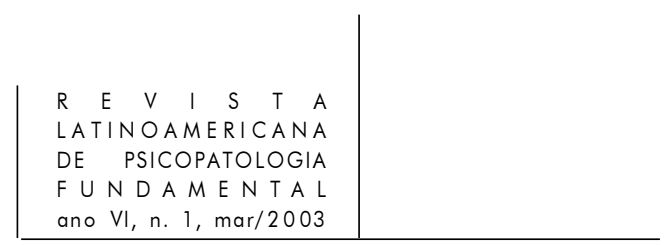

$>$ resistência ativa às tentativas externas de abertura dos olhos;

$>$ manutenção da resposta a estímulos dolorosos;

$>$ mudança de posição para evitar desconforto;

$>$ desvio dos globos oculares em direção ao solo.

- Comportamento de evitação durante a crise ou no período pós-crise imediato (presença de resistência à contenção física).

- Intensificação dos movimentos convulsivos quando se impõe alguma contenção; o paciente parece "lutar" contra a contenção.

- Choro, conversas, obscenidades, gritos durante ou logo após a crise.

- Comportamento agressivo dirigido, durante a crise.

- Término gradual.

- Ausência de confusão mental no período pós-ictal.

- Preservação do estado vigil, mas a autoconsciência pode estar comprometida.

- Ausência de queixas subjetivas pós-ictais (pode sorrir ou rir após a crise).

- Recuperação mnésica detalhada de eventos ocorridos durante a crise.

- O evento pode ser induzido por sugestão (solução salina endovenosa).

- Pode ocorrer desorientação autopsíquica após o evento (sugerindo quadro nítido de transtorno dissociativo).

- Muitas vezes, crises com "quedas" ocorrem em posição ou local confortável.

- Cianose é evento raro durante as crises pseudo-epilépticas.

- Imediatamente após a crise pseudo-epiléptica não ocorre resposta plantar em extensão.

- Raramente há mordeduras de língua; quando há, são mínimas, envolvendo a ponta e lábios, não os lados da língua.

- Pródromos variáveis a cada crise, com grande número de sintomas somáticos e visuais sugestivos de crise pseudo-epiléptica.

\section{Conduta psiquiátrica nas crises pseudo-epilépticas}

Pela própria natureza psicopatológica em questão, os pacientes com crises pseudo-epilépticas necessitam de uma abordagem psicanalítica para a superação de seu quadro mórbido, sendo que este tratamento é bastante complexo, principalmente no início, pelo fato do paciente exprimir seu sofrimento psíquico (e a satisfação pulsional propiciada pelo sintoma) mais através de fenômenos psicomotores (as crises "convulsivas") do que pelo discurso, convertendo em sinais somáticos os conteúdos psíquicos. Além disso, o caráter profundamente regressivo desse quadro e os ganhos que proporciona dificultam que o indivíduo considere o sofrimento implicado em seus sintomas como algo que coloque em 


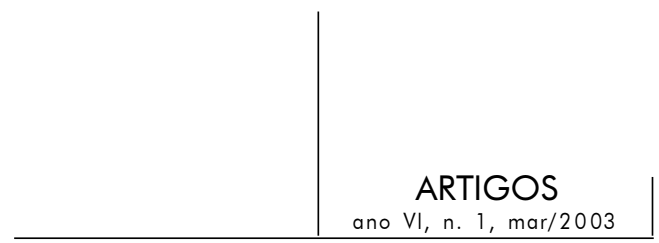

questão sua posição subjetiva. Evidentemente, o mero controle dos sintomas não pode ser considerado como o objetivo central do trabalho psicoterapêutico, uma vez que a própria presença de crises pseudo-epilépticas indica a existência de conflitos psíquicos inconscientes, intensos e, por vezes, arraigados à personalidade do sujeito.

Uma abordagem clínica eficaz não se limitaria a ajudar o paciente a comunicar seu sofrimento apenas por meio de símbolos verbais, ou seja, do discurso empregado como simples via de descarga de emoções. Seria necessário a implementação de situações que permitissem ao paciente compreender que a crise, em si, representa um sofrimento que se manifesta além da palavra, isto é, através das próprias "convulsões". O paciente revela seu sofrimento mais pelos sinais corporais do que pelo discurso, como afirmou Berlinck (2000), mostrando sua crise - e simbolizando seus conflitos - pelos movimentos psicomotores desordenados, pela "convulsão". A elaboração desta simbolização patológica constitui, portanto, o foco da ação terapêutica.

Outra forma de tratamento freqüentemente utilizada nessas situações é o psicodrama, por intermédio do qual o paciente vivencia seus processos emocionais simbolizando seu sofrimento psíquico nas "convulsões" psicogênicas, com a programação de ações não-verbais que auxiliem o sujeito a compreender as manifestações semiológicas da sua doença (Stella, 2000).

Do ponto de vista psiquiátrico, há a necessidade de tratamento de comorbidades freqüentemente associadas às crises pseudo-epilépticas, sobretudo a depressão grave com risco de suicídio e outros transtornos mentais, com a utilização de medicação específica quando pertinente.

O tratamento conjunto das crises - tanto as epilépticas como as pseudoepilépticas - tende a propiciar melhora ao paciente, até porque ambas influenciamse mutuamente agravando o sofrimento quando não tratadas adequadamente (Krahn et al., 1995; Betts, 1997).

\section{Comentários finais}

Vários aspectos podem ser considerados ao final deste trabalho. Um deles consiste na possibilidade de o comprometimento cerebral provocar ambas as crises - as epilépticas e as pseudo-epilépticas. Um percentual significativo de pacientes epilépticos, com crises parciais complexas de lobo temporal, de difícil controle, também costuma apresentar crises pseudo-epilépticas. O diagnóstico diferencial de ambos os tipos de crises nem sempre se torna procedimento fácil. Há controvérsias por parte de psiquiatras e neurologistas se a doença cerebral, no 


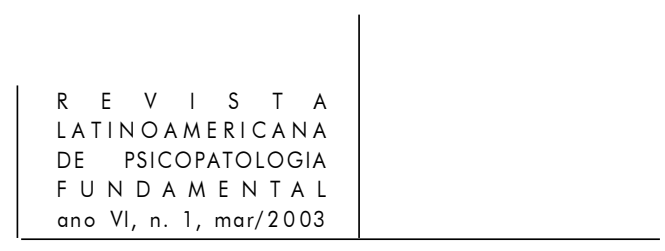

caso das crises epilépticas, predisporia ao aparecimento de crises pseudoepilépticas. Alguns estudos revelam a tendência de que os distúrbios da atividade bioelétrica cerebral contribuiriam para a manifestação clínica tanto das crises epilépticas propriamente ditas, como das crises pseudo-epilépticas (Thomas and Trimble, 1997). Entretanto, há a necessidade de esclarecimento sobre como as alterações cerebrais provocariam as crises pseudo-epilépticas.

Outro aspecto a ser destacado consiste na importância da história de abuso emocional, físico ou sexual na infância ou na adolescência como fator que predispõe ao desencadeamento das crises pseudo-epilépticas, fenômenos estes freqüentemente constatados nos Serviços de Emergência Psiquiátrica. Além disso, eventos traumáticos severos que geram sofrimento psíquico importante também podem predispor ao desenvolvimento de reações dissociativas e conversivas em pacientes epilépticos (Gross, 1986).

Estudos mostram que pacientes epilépticos, principalmente aqueles com epilepsia de lobo temporal, estão mais expostos, do que a população geral, a distúrbios psiquiátricos, particularmente, às crises pseudo-epilépticas (Marchetti, 1998).

Do ponto de vista do funcionamento mental, a estrutura psíquica frágil acometida por situações conflitivas inconscientes não resolvidas, com transtornos de personalidade, com história de abuso na infância e com sintomas depressivos, representa fator de risco significativo para o desencadeamento de crises pseudoepilépticas.

Do ponto de vista psicossocial, preconceitos e estigmas também têm sua parcela no desencadeamento dessas crises, ao restringirem as oportunidades de engajamento profissional e cultural do paciente, aumentando níveis de regressão e de ansiedade.

Do ponto de vista neurobiológico, alterações da atividade bioelétrica em estruturas límbicas do lobo temporal, principalmente em hipocampo e amígdala (responsáveis por crises parciais complexas), também geram sofrimento psíquico, predispondo o paciente ao surgimento de transtornos dissociativos e conversivos associados a crises epilépticas.

De um lado, a ausência do diagnóstico das crises pseudo-epilépticas em pacientes epilépticos e o não tratamento das mesmas conduzem ao comprometimento nas relações interpessoais e ao surgimento de estigmas que prejudicam o indivíduo a longo prazo. Assim, são imprescindíveis o diagnóstico precoce e o tratamento dessas crises. Por outro lado, a melhora da condição mental do indivíduo reflete-se na diminuição da gravidade e da frequiência das crises epilépticas genuínas, contribuindo para a melhora de sua qualidade de vida. 


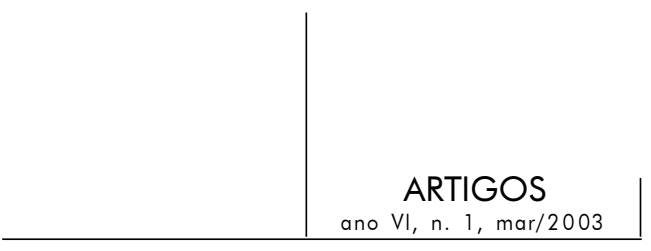

Referências

AlPER, K. Nonepileptic seizures. Neurology Clinic, v. 12. n. 1, p. 153-73, 1994.

American Association of Psychiatry (APA). Manual Diagnóstico e Estatístico de Transtornos Mentais - DSM-IV. Trad. Dayse Batista. 4. ed. Porto Alegre: Artes Médicas, 1995.

Berlinck, M.T. Comunicação Oral. V Congresso Brasileiro de Psicopatologia Fundamental. Campinas, 2000.

Betts, T. Conversion Disorders. In: Engel, J.JR.; Pedley, T.A. (Editors). Epilepsy: A Comprehensive Textbook. 3 Volumes. Philadelphia/New York: Lippincott/Raven Publishers, 1997.

Сharcot, J-M. A grande histeria ou hístero-epilepsia. Revista Latinoamericana de Psicopatologia Fundamental, v. II, n. 3, p. 166-72, set./1999.

Dalgalarrondo, P. Psicopatologia e semiologia dos transtornos mentais. Porto Alegre: Artes Médicas, 2000.

Delasiauve L-J. (1854). Traité de l'épilepsie. Paris: Masson.

Ferreira, A. B. de H. Novo Aurélio Século XXI - Dicionário da Língua Portuguesa, 3. ed. Rio de Janeiro: Nova Fronteira, 1999.

Fiszman, A.; Menezes, M.G.P.T.; Gomes, M.M. Psicopatologia ictal e interictal, crises não epilépticas psicogênicas. Revista Brasileira de Neurologia, v. 33, n. 2, p. 1019, 1997.

Freud, S. (1908). Hysterical phantasies and their relation to bisexuality. In: The Pelican Freud Library, Vol. 10: On Psychopathology. London: Pelican Books, 83-94, 1979.

Gross, M. Hysterical seizures - a sequel to incest during adolescence. International Journal of Adolescence Medical Health, v. 2, n. 1, p. 39-51, 1986.

Gumnit, R. The Epilepsy Handbook. New York: Raven Press, 1994.

Kaplan, H.I.; SAdock, B.J.; GrebB, J.A. Compêndio de psiquiatria: ciências do comportamento e psiquiatria clínica. 7. ed. Porto Alegre: Artes Médicas, 1997.

Kirmayer, L. J. \& Santhanam, R. The anthropology of hysteria. In Halligan, P. \& Bass, C. (org.) Conversion disorder. Oxford: Oxford University Press, 2000.

Krahn, L.E.; Rummans, T.A.; Sharbrough, F.W.; Jousey, S.G.; Cascino, G.D. Pseudoseizures after epilepsy surgery. Psychosomatics, v. 36, n. 5, p. 487-93, 1995.

Kristensen, O.; Alving, J. Pseudoseizures - risk factors and prognosis. Acta Neurologica Scandinava, v. 85, p. 177-80, 1992

Lelliot, P.T.; Fenwick, P. Cerebral Pathology in pseudoseizures. Acta Neurologica Scandinava, v. 83, p. 129-32, 1991.

Lesser, R.P. Psychogenic Seizures. In: Pedley, T.A.; Meldrum, B.S. (eds.). Recent Advances in Epilepsy. Edinburgh: Churchill Living-Stone, 273-296, 1985.

Marchetti, R. L. Aspectos Psiquiátricos da Epilepsia. In: Costa, J.C.; Palmini, A.; Yacubian, E.M.T.; Cavalheiro, E. (Editores). Fundamentos neurobiológicos das epilepsias: aspectos clínicos e cirúrgicos. 2 volumes. São Paulo: Lemos Editorial, 1998. 
OANA, Y. Epileptic seizures and Pseudoseizures from the viewpoint of the hierarchy of consciousness. Epilepsia, 39 (Suppl. 5), p. 21-5, 1998.

OMS. Organização Mundial de Saúde. Classificação de Transtornos Mentais e de Comportamento da CID-10 - Descrições clínicas e Diretrizes diagnósticas. Trad. Dorgival Caetano. Porto Alegre: Artes Médicas, 1993.

Pereira M.E.C. Introdução a "Da anorexia histérica", de Charles Lasègue. Revista Latinoamericana de Psicopatologia Fundamental, v. I, n. 3, 155-7, set./1998.

C'est toujours la même chose: Charcot e a descrição do Grande Ataque Histérico. Revista Latinoamericana de Psicopatologia Fundamental, v. II, n. 3, p. 159-65, set./1999.

Ramandan, Z.B.A. A histeria. São Paulo: Ática, 1985.

SCHENK, L.; BEAR, D. Multiple personality and related dissociative phenomena in patients with temporal lobe epilepsy. American Journal of Psychiatry, v. 138, n. 10, p. 1311-6, 1981.

Stella, F. Comunicação oral. V Congresso Brasileiro de Psicopatologia Fundamental. Campinas, SP, 2000.

Thomas, L.; Trimble, M.R. Dissociative Disorders. In: Engel, J.E.; Pedley, T.A. (Editors). Epilepsy: A Comprehensive Textbook. 3 volumes. Philadelphia/New York: Lippincott/Raven Publishers, 1997.

Trillat, E. História da histeria. São Paulo: Escuta, 1991.

\section{Resumos}

Los autores discuten las características semiológicas y clínicas de las crisis no epilépticas psicógenas y el papel de elementos de naturaleza inconsciente en la génesis de esos fenómenos. Esas características constituyen una condición psicopatológica relativamente frecuente en centros de atención a pacientes portadores de epilepsia y en servicios de emergencia psiquiátrica. El diagnóstico diferencial entre ambos cuadros no siempre representa una tarea fácil y exige del clínico conocimiento de las manifestaciones semiológicas, tanto de crisis genuinamente epilépticas, como de crisis conversivas de naturaleza esencialmente psicógena.

Palabras clave: Trastorno conversivo, crisis pseudo-epilépticas, crisis psicógenas, semiología

Les auteurs discutent les caractéristiques sémiologiques et cliniques des crises pseudo-épileptiques et le rôle d'éléments de nature inconsciente dans la genèse de ces phénomènes. Ces crises constituent des cas cliniques assez fréquents dans les centres de traitement de patients porteurs d'épilepsie et dans les services d'urgence psychiatrique. Il n'est pas toujours facile d'établir un diagnostic différentiel entre ces 


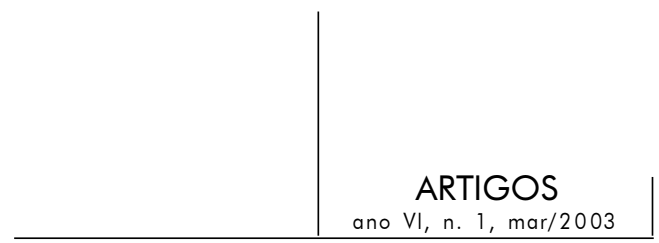

deux tableaux cliniques, car cela exige de solides connaissances sur les symptômes sémiologiques des vraies crises d'épilepsie et des crises de conversion, de type pseudoépileptique.

Mots clés: Trouble de conversion, crises pseudo-épileptiques, hystérie, sémiologie

The authors discuss the semiological and clinical characteristics of pseudoseizures and the role of unconscious psychological contents in the genesis of these phenomena. Pseudoseizures are relatively frequent clinical conditions in epilepsy centers and in psychiatric emergency services.

The differential diagnosis of patients showing seizures or pseudoseizures is not always an easy task, and demands knowledge about specific semiological symptoms of epileptic events and conversive episodes.

Key words: Conversive disorders, pseudoseizures, hysteria, semiology 